\title{
A Tecnologia das Rêdes de Informática
}

\section{Situação Atual e Perspectivas para o Futuro}

\author{
GEORGE J. FEENEY \\ da General Electric Company \\ Tradução de Luiz Fernando \\ do Coutto Nazareth
}

(Fonte: Informatique, 1970 - Paris)

\section{EXPLANAÇÃO FEITA NO CONGRESSO SÔBRE ADMINISTRAÇĀO AUTOMATIZADA E HUMANISMO, EM SETEMBRO DE 1969}

Dentre todos os importantes progressos realizados nestes últimos anos no domínio dos computadores, o mais revolucionário, aquêle cujas conseqüências para o futuro são realmente incalculáveis, é o aparecimento da tecnologia das rêdes de informática ou, dito de outro modo, a integração do processamento e das transmissões. Êste aspecto da informática, batizado, conforme o caso, como "tempo parcial", "processamento por acesso direto", "processamento de massa à distância", "teleprocessamento"1 ou "rêde de informática", e que desempenhava, por volta de 1960, um papel restrito, secundário e especializado, tornou-se o centro de interêsse dos meios industriais.

Se bem que o número de rêdes atualmente em operação, em todo o mundo, continue relativamente pequeno, o indice de crescimento dêsse setor é quatro ou cinco vêzes maior que
- das instalações convencionais de "processamento local de massa ou por grupo".2 Muitos acreditam que as rêdes de informática terminarão por tornar-se o modo de processamento mais difundido: a própria energia elétrica, que outrora provinha de centrais individuais, instaladas no estabelecimento a que deviam servir, é agora produzida em imensas centrais e fornecida, a seguir, a milhões de individuos, por meio de rêdes de transmissão e de distribuição.

A finalidade dêste artigo ě examinar a situação atual $e$ as perspectivas, para o futuro, da tecnologia das rêdes de informática, e indicar algumas das aplicações em que o proces-

1. O têrmo "teleprocessamento" (teleprocessing) é marca registrada da I.B.M. (N. do T.)

2. A expressăo "processamento por grupo" (batch processing), designa a técnica pela qual os itens a serem processados sấo codificados e reunidos em grupos, antes do processamento. (N. do T.) 
samento por rêdes oferece vantagens imediatas. Mas convém, inicialmente, identificar os fatôres estruturais determinantes, que, a nosso ver, subtendem e suscitam a rápida adoção dessa nova tecnologia.

FATÔRES DE DESENVOLVIMENTO

O primeiro dêsses fatôres é a produtividade do usuário. $\mathrm{Na}$ medida em que os computadores, ao longo dos dez últimos anos, tornaram-se cada vez mais potentes, os centros de processamento passaram a receber um volume sempre crescente de tarefas, que lhes eram confiadas por um número cada dia mais elevado de usuários. A despeito da enorme capacidade dos computadores atuais, muitos de nós evocam, não sem nostalgia, os primeiros tempos, quando - quaisquer que fôssem as limitações dos sistemas - era possivel ter-lhes acesso, muito fàcilmente, e resolver os problemas através de um diálogo direto. Hoje, um centro de processamento-padrão mais parece uma repartição dos correios, onde dezenas de pessoas se afanam em tratar - ou maltratar - centenas ou mesmo milhares de pacotes de cartões de entradas, de listings ${ }^{3}$ de saída, de bobinas de fita etc. e onde uma burocracia operacional ergue uma sólida barreira entre o usuário e o computador.

Nesses centros, as filas de espera formam-se, inevitàvelmente, nas diversas fases do processamento e uma tarefa que requer normalmente trinta segundos do tempo do computador, pode requerer 24 horas de tempo total de resposta. Para muitos cálculos de rotina, essa demora não acarreta maiores conseqüências, mas pensem em suas possiveis incidências no caso de aplicações que requerem um estreito diálogo entre o usuário e o computador. Por exemplo, a concepção dos transformadores de grande potência foi consideràvelmente aperfeiçoada pela análise em computador, que traduz os parâmetros de concepção em indicações de custo e de desempenhos. Mas se são necessárias dez iterações para obter um modêlo aceitável e se cada uma dessas iterações depende da análise dos resultados anteriores, serão necessárias duas semanas para concluir um estudo que teria podido ser concluído em uma ou duas horas, se o engenheiro tivesse podido manter-se em comunicação direta e permanente com o computador.

Ora, o que o "tempo parcial" proporciona ao usuário é precisamente o acesso direto e permanente ao computador, por intermédio de dezenas de terminais locais conectadas simultâneamente a um computador central. Êste método é, em verdade, o inverso dos processos tradicionais: anteriormente, o engenheiro estudava vários projetos paralelamente, para permitir ao computador executar uma só tarefa, de princípio ao fim. Ora, no contexto de uma rêde, o computador central processa diversas tarefas paralelamente e permite ao engenheiro executar uma só, de ponta a ponta, dedicando uma atenção constante ao esfôrço criador, constituído pela escolha das alternativas, com base nos resultados obtidos. Em conseqüência, o usuário registrará um aumento sensível de sua produtividade, bem como uma redução substancial do tempo de execução das tarefas. Êste aumento da produtividade, graças ao acesso direto, vem

3. Os textos que aparecem em inglês no original, foram mantidos em inglês (N. do T.) 
reforçar decisivamente o caráter de utilidade e de necessidade dos computadores, em setores tais como a planificação, a computação, a análise estatística, a programação e em diversos outros setores fundamentais, como a engineering.

O segundo fator determinante é o que se poderia denominar a logística informática. Em uma sociedade industrial vasta, complexa e geogràficamente dispersa, certos trabalhos de processamento muito importantes requerem a coleta de entradas, em diferentes pontos, e a distribuição dos resultados por um grande número de estações. Ora, os sistemas convencionais de computação não atendem a essas necessidades. Se você desejar utilizar um computador dêsse tipo, você terá de ir a êle, tal como os amigos iam ter ao oráculo de Delfos. Os computadores convencionais acham-se na impossibilidade absoluta de encarregarem-se, sòzinhos, das interações cotidianas entre os programas de produção de uma usina, as previsões de saída e de transporte de suas centenas de artigos, bem como de satisfazer às exigências de milhares de clientes, e é necessário, para isto, recorrer a sistemas auxiliares de transmissão de mensagens, sistemas dispendiosos, incômodos, causadores de erros e muito lentos.

A tecnologia das rêdes - graças à integração das transmissões e do processamento, por ela realizada - permite interações dinâmicas entre várias atividades diferentes, geogràficamente dispersas e descentralizadas, e isto por intermédio de terminais distanciados, todos com acesso aos cadastros de programa e de dados da unidade central. Convém sublinhar que se trata, ainda, de sistemas universais, não especializados, que diferem, por exemplo, dos sistemas de reservas das companhias aéreas e que possuem uma flexibilidade suficiente para servir de base a aplicações complexas de teleprocessamento, sujeitas a modificações progressivas e graduais, ditadas pela experiência.

O terceiro fator determinante é a economia dimensional. Uma das descobertas da indústria dos computadores ao longo dos últimos vinte anos, é que, de um modo geral, o custo da unidade de trabalho-computador decresce à medida em que as dimensões do equipamento aumentam. Um sistema de computação que custe duas vêzes mais, produzirá cêrca de quatro vêzes mais trabalho. Mesmo se adicionarmos os custos das transmissöes entre a estação do usuário $\theta$ o computador, e vice-versa, bem como o custo do equipamento terminal do usuário, continua a ser econômicamente mais vantajoso, para uma emprêsa cujas necessidades sejam moderadas, alugar sua parte de serviço de um grande computador, que adquirir seu próprio equipamento.

Além dessa redução dos custos de processamento, a rêde permite realizar três tipos de economia, menos especulares, mas igualmente importantes.

A primeira diz respeito ao custo da capacidade de reserva. Com efeito, quando o usuário pretende adquirir um computador, deve prever uma capacidade suficiente, que leve em conta o crescimento previsível das necessidades de processamento, em sua emprêsa. Ora, esta despesa de previsão poderá ser evitada se o usuário optar por adquirir, gradativamente, a uma rêde de informática, a capacidade de processamento de que necessite, caso 
em que pagará, cada mês, apenas a capacidade por êle efetivamente utilizada.

A segunda economia potencial refere-se à disponibilidade e à confiabilidade 4 do computador. Se bem que seja difícil fornecer uma estimativa precisa da confiabilidade de um computador, é evidente que poucos dirigentes de emprêsas dispõem de recursos para adquirir o equipamento suplementär e para contratar o pessoal auxiliar indispensável para assegurar a todo sistema de processamento um funcionamento sem falhas. Ora, uma rêde de informática, graças a sua capacidade e aos enormes investimentos em sistemas de transmissão, computadores e pessoal especializado de que se beneficia, está em condições de oferecer essa disponibilidade e essa confiabilidade optima, tanto aos grandes quanto aos pequenos usuários.

A terceira economia decorre do nivelamento das cargas de trabalho diurno. Na medida em que a comunicação pessoal, direta, constitui um modo de utilizaçăo característica da rêde - $\Theta$ nós procuramos demonstrar que esta é uma de suas mais importantes possibilidades - a rêde de informática deve poder adaptar-se aos hábitos humanos, por exemplo, ao trabalho exclusivamente diurno (em geral) e à interrupção para a refeição do meiodia. Disto resulta que o sistema é submetido a uma carga máxima de trabaIho pela manhã e pela tarde. Mas se a rêde cobre diversas zonas horárias, os períodos de máximo consumo combinar-se-ão, e a carga total aumentará proporcionalmente à capacidade máxima. Havendo uma carga total suficiente e um equilibrio razoável entre as zonas horárias, êsse efeito de nive- lamento de carga pode, freqüentemente, justificar os custos de transmissöes a longa distância, em uma rêde de informática muito extensa.

\section{A TECNOLOGIA ATUAL}

Tôda rêde de informática compreende, normalmente, quatro subconjuntos funcionais principais: os terminais, as transmissões, a unidade central de processamento e as unidades de armazenamento. Começaremos por um breve exame do estado atual da tecnologia de cada um dêsses subconjuntos, depois descreveremos, em suas grandes linhas, certos sistemas completos, cuja utilização se generalizou.

OS TERMINAIS

Os terminais constituem a interface local entre o usuário e a rêde.

Antes de mais nada, existem diferentes tipos de terminais de baixa velocidade. Os dispositivos de entrada por teclado e de saída por segmentos impressos, representados nos Estados Unidos pelo Teletipo Modêlo 33 é, de longe, o mais difundido, hoje em dia. Só no território norte-americano, estima-se em mais de 20.000 o mínimo de teleimpressores atualmente em uso. Êsses dispositivos, geralmente equipados com uma leitora 5 e uma perfuradora de fita, são fáceis de manejar, relativamente pouco dispendiosos, e seu indice de falhas é mínimo; entretanto, são lentas (dez caracteres por segundo), barulhentas, com pouca mobilidade, e oferecem, em geral, um número limitado de caracteres: não

4. Neologismo que vem sendo largamente empregado no Brasil, para traduzir os equivalentes reliability (inglês) fiabilité (francês).

5. A leitora detecta e transmite à unidade central do computador, os furos de um cartão perfurado (N. do T.) 
podem, por exemplo, imprimir minúsculas.

Um segundo tipo de terminais, cuja utilização se está difundindo, combina a entrada por teclado com a saída por visor de tubo catódico. Essses sistemas oferecem saídas mais rápidas, da ordem de 100 caracteres por segundo, ou mais, e oferecem, ademais, a vantagem de um visor e de um funcionamento silencioso. Em contrapartida, custam cêrca de duas vêzes mais caro que os teleimpressores, oferecem um espaço de mostragem visual restrito -1.000 a 2.000 caracteres - e não oferecem nenhum modo direto de conservar registro das saídas sob forma de documentos impressos.

As traçadoras de curvas diferenciais, de uma precisão da ordem de uma fração de milimetro, são igualmente utilizadas como terminais on line e produzem uma saída gráfica direta.

Por fim, uma variedade de dispositivos muito rápidos, tais como os sistemas de leitora de cartões e impressoras lineares, ${ }^{6}$ são utilizados atualmente. Segundo as características do terminal e a capacidade da linha de transmissão utilizada, êsses sistemas atingem velocidades que vão de 100 a 400 caracteres por segundo e custam de oito a vinte vêzes mais que um teleimpressor.

\section{AS TRANSMISSÕES}

O subconjunto das transmissōes liga os terminais dos usuários às rêdes de informática. Por intermédio de modems (dispositivos de modulação-demodulação), o fluxo de bits digitais proveniente do terminal é convertido em sinais de frequeência vocal, que são transmitidos pela linha telefônica nor- mal, depois convertidas em saídas digitais, na estação receptora.

Esta fórmula é suficiente, de um modo geral, para atender às necessidades de ligação de rêdes limitadas, que funcionam, sobretudo, dentro de uma zona geográfica restrita. De fato, sem as linhas telefônicas existentes, a evolução inicial de sistemas de tempo parcial e de processamento por grupos à distância teria sido retardada por vários anos.

Mas, à medida que as rêdes se desenvolvem, cobrindo regiões mais vastas, a tecnologia telefônica existente, embora conservando seu caráter de absoluta necessidade, torna-se cada vez mais insuficiente.

Há diferenças fundamentais entre as necessidades das rêdes de informáti$\mathrm{ca} e$ as possibilidades dos sistemas telefônicos. A transmissão da voz mobiliza uma faixa multo larga. Para atender às condições de operação normais, de uma ligação, a capacidade de uma linha telefônica deveria ser de cêrca de 1.800 bits por segundo, isto é, mais de dezesseis vêzes a de um teleimpressor que funcionasse à velocidade de 10 caracteres por segundo. A distâncias curtas, em que o custo das linhas é baixo, essa subutilização não tem consequeências graves, é mais que compensada pela flexibilidade e pela comodidade do sistema telefônico. Mas, no caso de ligações interurbanas, o sistema não é econômico. Êsse proble$\mathrm{ma}$ fol solucionado pelos multiplexores

6. Dispositivos que permitem imprimir uma linha inteira, de cada vez. Os impressores de alta velocidade imprimem linhas com 120 a 160 caracteres, à razăo de 100.000 linhas por hora. (N. do T.)

7. Contraçáo da expressăo binary unit ou binary digit (unidade binária ou dígito binário). (N. do T.) 
de transmissões, cujo emprêgo se está generalizando.

Êsses multiplexores dividem a capacidade das linhas de freqüência locais (quer se trate de divisão temporal quer de divisão de freqüências) em cêrca de uma dúzia de vozes individuais, capazes, cada uma delas de servir um terminal distinto. Êsses dispositivos ampliam consideràvelmente o alcance de utilização econômica das terminais de baixa velocidade - até várias centenas de quilômetros.

O sistema telefônico possibilita transmissões contínuas em larguras de faixas fixas, e tolera interferências ocasionais ou erros de linha, mas a transmissão por rêde se efetua sob forma de mensagens reservadas (cujo caso típico é o de uma "linha de dados"), que são emitidas a intervalos irregulares, e requerem velocidade de transmissão que variam de dez caracteres por segundo até várias centenas de caracteres por segundo; além disso, as rêdes toleram muito menos erros que os sistemas telefônicos.

Êsses problemas, associados aos imperativos econômicos das transmissões, ultrapassando as possibilidades dos mutiplexores, conduziram ao emprêgo de concentradores de transmissõe̊s.

Um concentrador é constituido por um pequeno computador, muito rápido, que tem, de um lado, uma centena de linhas de terminais muito lentas e, de outro lado, algumas linhas de alta velocidade. Essas linhas de alta velocidade, que requerem modems $^{8}$ de capacidade superior e uma calibragem especial dos circuitos telefônicos, acham-se agora disponiveis, com uma capacidade de 2.400 bits por segundo, que, em um futuro próximo, deveria atingir de 4.800 a 9.600 bits por segundo. Normalmente, as Iinhas de alta velocidade são linhas terrestres especiais, mas, no caso do tráfego intercontinental, recorre-se a ligações por satélites. Para as entradas de baixa velocidade, o concentrador analisa os caracteres provenientes de cada linha e reúne a mensagem completa, definida por uma convenção de fim de mensagem - que pode ser a tecla de retôrno do carro, de um teclado do teleimpressor depois coloca a mensagem em uma fila de espera de saída, após haverse adicionado certas informações complementares, especialmente a origem da mensagem, e dados de contrôle baseados no conteúdo da referida mensagem.

A parte de saida a alta velocidade seleciona uma linha disponivel e transmite sucessivamente as mensagens $\mathrm{co}^{-}$ locadas na fila de espera. Na outra extremidade, as mensagens que chegam pelas linhas de alta velocidade são imediatamente conferidas. Se não contêm êrro, uma confirmação é enviada de volta, e a mensagem é liberada da fila de saída do concentrador fonte. Em caso de detecção de êrro, é solicitado ao concentrador uma retransmissão da mensagem.

As rêdes mals importantes, atualmente existentes, utilizam vários concentradores periféricos, que servem, cada um dêles, os terminais de uma determinada região, por intermédio de linhas locais multiplexadas ou individuais. Os concentradores periféricos

8. Modem: contraçáo de "moduladordemodulador" (modulator-demodulator); dispositivo para converter uma forma de sinal em outra, a fim de assegurar a compatibilidade de equipamentos. 
dependem de um ou dois concentradores centrais, que, por sua vez, estabelecem a conexão com a instalação central de processamento.

Em outras palavras: quando a distância $e$ o volume do tráfego justificam o investimento em um equipamento suplementar, a utilização do concentrador oferece numerosas vantagens sôbre a multiplexagem. Os erros de transmissão são nitidamente menos numerosos, e a continuidade do serviço é melhorada, de vez que, se uma das linhas de alta velocidade se encontrar temporàriamente fora de serviço, o tráfego será encaminhado automàticamente pelas outras linhas. A técnica de concentração das linhas, denominadas "de armazenamento e de emissão", logra, ademais, um aumento do rendimento das linhas de longa distância, pois estas sòmente veiculam o tráfego ativo. As pausas dos usuários nos terminais e os períodos de inação entre as saídas reais do computador são absorvidas pelas linhas de baixa velocidade do concentrador. Observa-se, geralmente, que o fluxo do tráfego efetivo nos terminais lentos atinge uma média inferior à metade da velocidade optima real.

Assim, pois, a tecnologia atual das transmissões permite a uma rêde de informática servir, em bases econômicas, uma zona de uma extensão quase arbitrária. De um modo geral, para os terminais lentos, que funcionam a uma distância razoável e com um volume de tráfego suficiente, a multiplexagem reduz à metade os custos das comunicações a longa distância em linha única, e a combinação multiplexor-concentrador deveria reduzir êsses custos à sua quarta parte.
OS CENTROS DE PROCESSAMENTO

O terceiro subconjunto funcional de uma rêde de informática é constituido por um computador central que processa as informações e comanda a atividade da rêde. Utilizamos atualmente, como unidades centrais, sistemas de capacidade média, com velocidade da ordem de cem mil a dez milhōes de instruções por segundo, ciclos de memória da ordem de um micro-segundo ou menos, e capacidade de memória da ordem de cem mil a um milhão de octets, sendo que essa capacidade é geralmente aumentada por uma extensão de memória de velocidade relativamente elevada - memória de massa, tambor ou memória a disco com cabeçote fixo, com capacidade compreendida entre um e dez milhões de octets. Êsses sistemas dispõem, ademais, de diversas unidades periféricas: consolos, unidades de fita e, menos freqüentemente, leitoras de cartões, impressoras lineares etc.

Com exceção dos cadastros, de que trataremos mais adiante, as rêdes de informática se distinguem dos sistemas convencionais de processamento local diferido 9 muito mais pelo software 10 que pelo hardware. 11

O software central comporta quatro elementos principais:

1) o sistema monitor, que controla a segurança e a acessibilidade da rêde e de seus recursos, e que programa e supervisiona tôdas as tarefas do sistema central;

9. Chama-se "processamento diferido" no sistema de teleprocessamento com respostas năo-imediatas, isto é, adiadas, diferidas. (N. do T.)

10. Programas. (N. do T.)

11. Equipamento. (N. do T.) 
2) diversos compiladores, que traduzem os programas elaborados pelo usuário em linguagem de máquina; 12

3) diversos programas de edição, que auxiliam o usuário na constituiçăo, na modificação, no armazenamento e na mostragem seletiva dos cadastros de programas e de dados;

4) uma biblioteca de programas e de subprogramas standard acessíveis aos usuários e que lhes permite enriquecer os programas que elaboram no momento.

Um sistema vasto pode servir mais de cem usuários ativos, cada um dos quais se encontre em uma fase de realização parcial de suas tarefas e deseje utilizar certos recursos do sistema. Os próprios usuários têm, cada um dêles, necessidades muito diferentes, no que se refere à linguagem de programação, à edição de cadastros e à mostragem. Não é surpreendente que um sistema com finalidade comercial tenha grande necessidade de software. Estima-se que o software central de uma rêdetipo pode comportar de cem mil a um milhão de instruções codificadas. Se nos basearmos nas normas atuais de rendimento de um programador, é necessário dispor de 50 a 500 anos de trabalho para obter uma programação completa, documentada, verificada e utilizável comercialmente. Existem, ho$j e$, diferenças fundamentais entre os recursos e os métodos de operação dos diversos sistemas. Em uma extremidade, encontramos os sistemas de tempo parcial, que, em geral, funcionam exclusivamente com terminais lentos, e oferecem os usuários um acesso contínuo e simultâneo, o que implica necessàriamente uma grande limitação da capacidade-memória, só podendo dispor o programa de cada usuário, de 8.000 a 16.000 palavras, e impöe a todos os usuários ativos um fracionamento do tempo da unidade de processamento em quanta relativamente reduzidos. Em conseqüência, cada usuário tem a impressão de dispor total e permanentemente de um sistema virtual mais lento e de menor capacidade que o sistema real. Esse método de operação convém particularmente a uma categoria - bastante vasta - de tarefas que implicam interações entre um ou vários usuários, seus programas e seus cadastros.

$\mathrm{Na}$ outra extremidade, encontram-se sistemas de processamento diferido à distância, que, em geral, funcionam exclusivamente com terminais muito rápidos e dão aos usuários acesso a todos os recursos da unidade central, segundo o princípio de "quem primeiro chegar, primeiro será servido", princípio que pode ser modificado por um processo de prioridades. Êsses sistemas são bastante apropriados ao processamento convencional, não implicam diálogo com o usuário e toleram tempos de resposta que vão de algumas horas até um dia inteiro.

Alguns sistemas, que aliam as vantagens dos dois tipos precedentes, começam a aparecer no mercado. Eles serão objeto, ulteriormente, de um exame pormenorizado.

\section{AS UNIDADES DE ARMAZENAMENTO}

O último subconjunto funcional de uma rêde de informática é o cadastro, que permite $o$ armazenamento perma-

12. Chama-se "linguagem de máquina". código utilizado para preparar as instruçōes para um computador (N. do $T$.) 


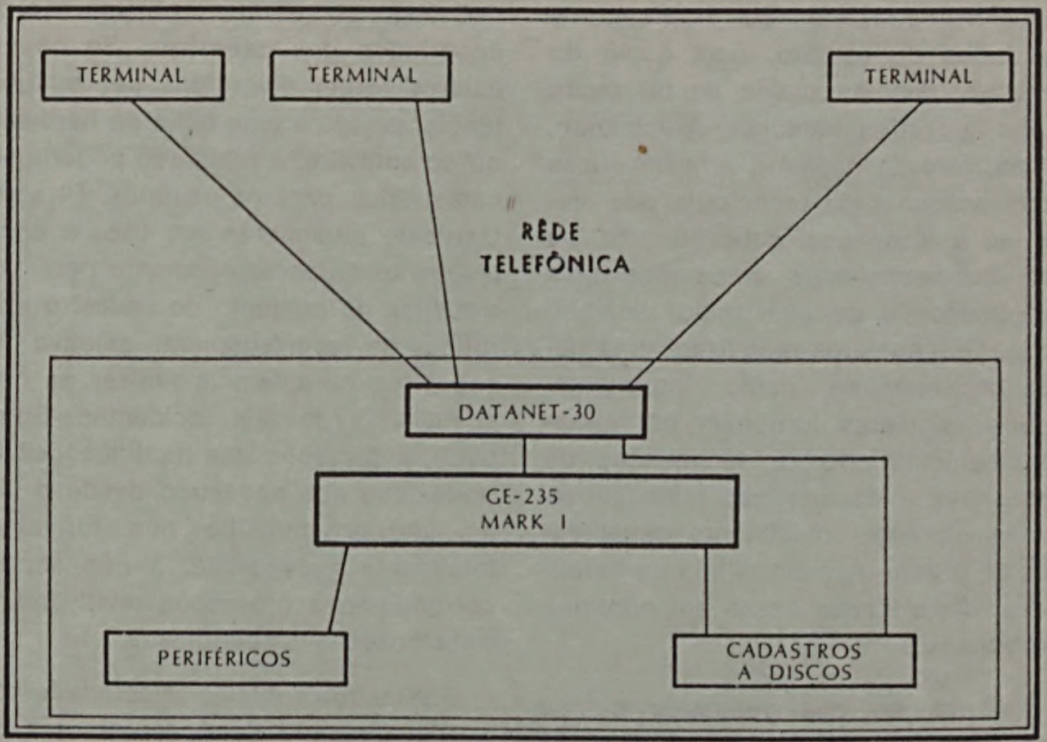

ESQUEMA 1

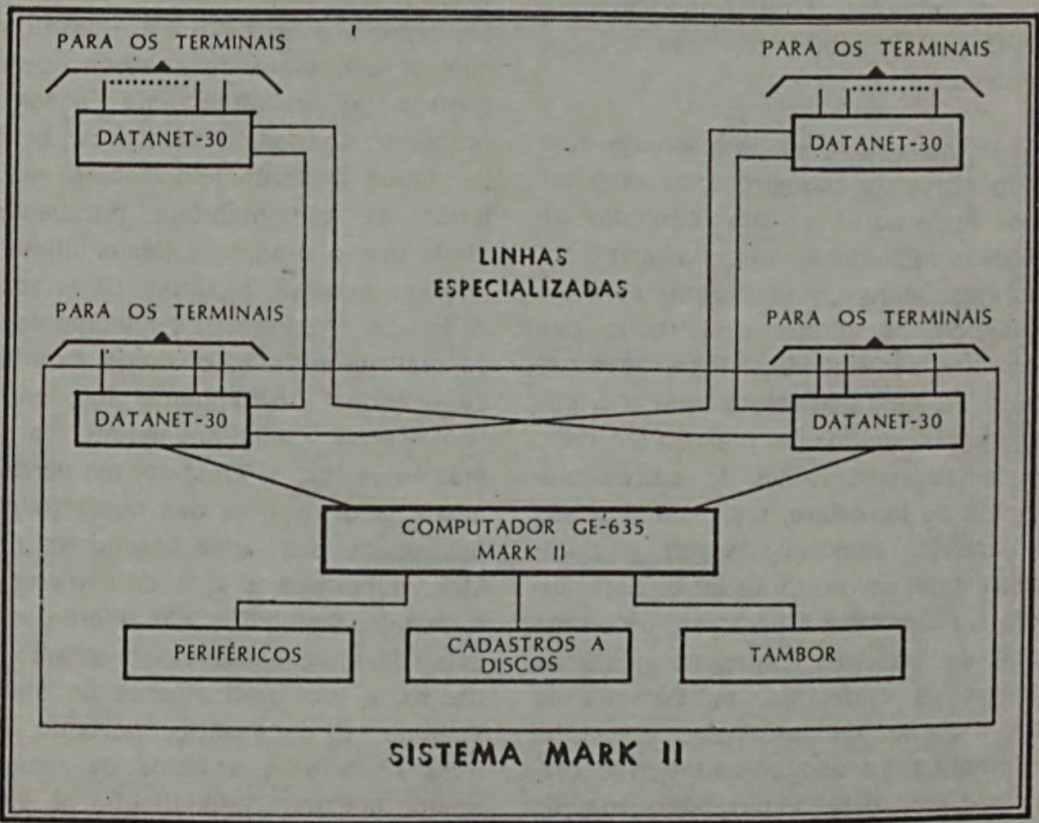


nente dos cadastros de programas e de dados do usuário, bem como do software, das instruções de utilização e dos cadastros-catálogos. Atualmente, o hardware de cadastro provém quase exclusivamente da tecnologia das memórias a disco com cabeçote fixo, ou dos disk-packs mais lentos mas mais econômicos e de uma maior flexibilidade. Os cadastros mobilizam uma capacidade-memória muito importante. Poucos sistemas fornecem um armazenamento inferior a 10 milhões de caracteres e os sistemas mais importantes oferecem atualmente capacidades da ordem de meio bilhão de caracteres, capacidades essas em contínua progressão.

A operação dos cadastros coloca problemas que se encontram entre os mais complexos do sofitware das rêdes de informática. Limitar-nos-emos a mencionar, brevemente, três dêsses problemas.

O primeiro acha-se relacionado com a segurança do cadastro. Uma rêde extensa pode servir a várias centenas de usuários individuais, que possuam, todos êles, milhares de programas e de cadastros de dados registrados nas memórias centrais. O sistema deve garantir, de modo absoluto, que, em circunstância alguma - mesmo em caso de falhas temporárias de certos elementos do hardware, um usuário possa ter acesso, sem autorização, aos cadastros de um outro usuário. Êste imperativo conduziu à elaboração de uma série de técnicas, entre as quais as senhas de cadastros, os códigos de identificação de terminais, a escrita automática no espaço-cadastro liberado por um usuário, a redundância do software e do hardware etc.
O segundo grande problema é o da integridade dos cadastros. Se os cadastros forem destruidos por inadvertência, devido a uma falha do hardware ou do software, o resultado poderia ser catastrófico para os usuários. Diversas técnicas, atualmente em uso, e especialmente o descarregamento periódico das fitas do conjunto do cadastro e as rotinas de recarregamento seletivo dos cadastros permitem minimizar as conseqüências de tais incidentes. Entretanto, a proteção das modificações introduzidas nos cadastros desde o último descarregamento não foi ainda totalmente assegurada, a não ser recorrendo-se a processos relativamente trabalhosos e dispendiosos.

O terceiro problema relacionado com a complexidade de operação dos cadastros é o do acesso múltiplo. Em virtude das características físicas do hardware dos cadastros, e a fim de minimizar o número de acessos aos cadastros, é absolutamente essencial proceder ao deslocamento de blocos de dados bastante importantes, no interior da zona-memória do usuário, ainda que o programa dêste último só leia ou escreva algumas palavras de cada vez. Além disso, é igualmente essencial permitir a diversos terminais de usuários (devidamente autorizados) ter acesso, simultâneamente, a um mesmo cadastro. Trata-se, em verdade, neste caso, de uma das possibilidades fundamentais de uma verdadeira rêde. Mas, suponhamos que dois ou vários terminais, instalados em diferentes locais, desejem escrever no mesmo cadastro, e isto pràticamente no mesmo instante. É necessário, portanto, bloquear o acesso a todos os usuários menos um, para impedir que os dados recentemente modificados sejam des- 


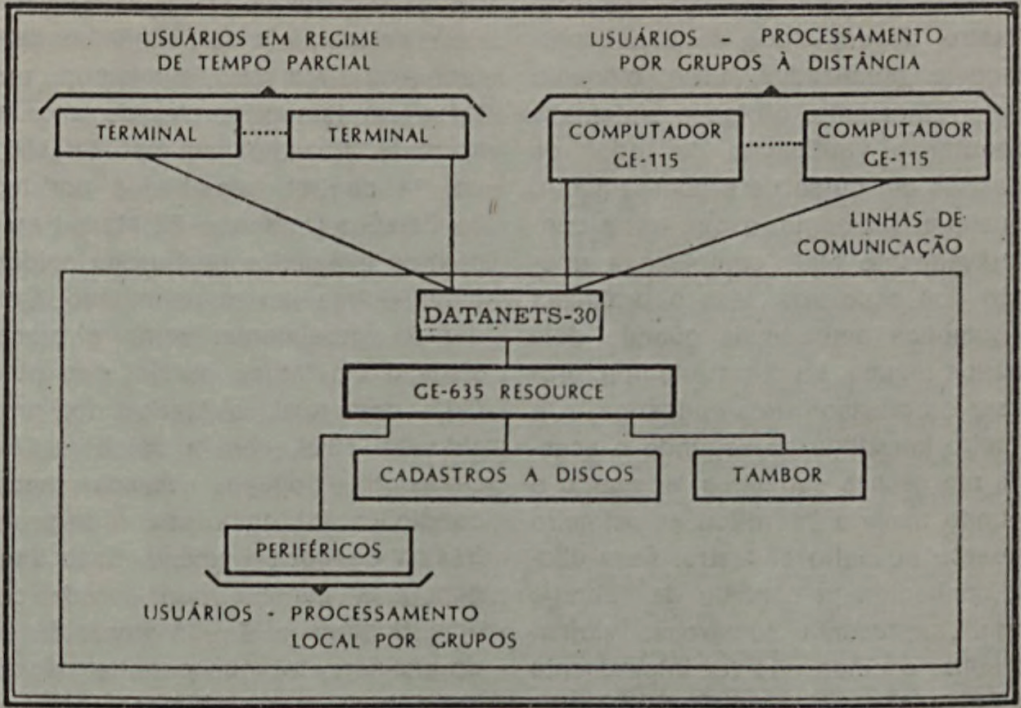

ESQUEMA 3

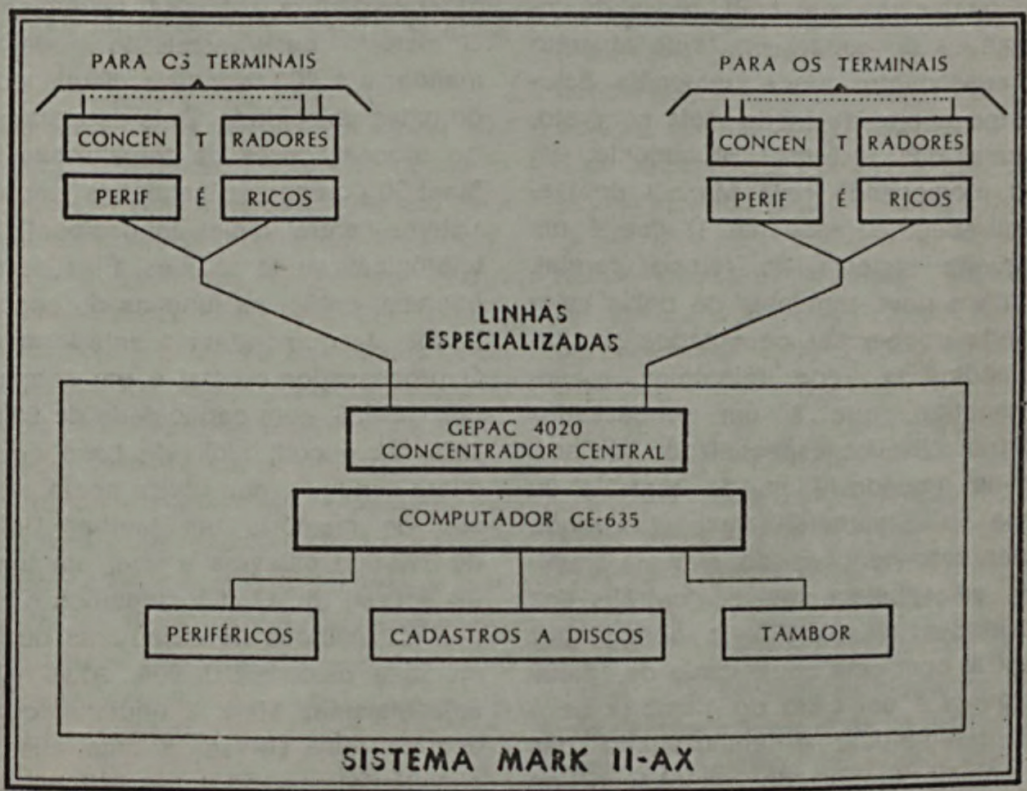


truídos no momento da reinscriçăo, no cadastro, de um bloco de dados parcialmente atualizados. Êsse bloqueio ou aferrolhamento, obriga o sistema a assegurar a verificação de todos os cadastros em curso de processamento, a qualquer momento, o que torna consideràvelmente mais complexa a operação dos cadastros. Mas o problema se complica ainda mais quando dois usuários tentam, ao mesmo tempo, processar os mesmos dois cadastros, e o primeiro interditou ao segundo o acesso a um dêsses cadastros, enquanto o segundo usuário interditou ao primeiro o acesso ao outro cadastro. Êsse dilema, conhecido pelo nome de "abraço mortal", apresenta numerosas variantes sutis, e ainda não foi inteiramente solucionado.

\section{OS SISTEMAS EM USO}

Examinamos, até aqui, rêdes de informática no quadro um tanto abstrato de suas quatro zonas funcionais. Estudemos agora, de modo mais concreto, alguns dos sistemas atualmente em uso, começando pelo Mark I da General Electric (esquema 1) que é um pequeno sistema de tempo parcial. Trinta e nove terminais de baixa velocidade podem ser conectados por intermédio da rêde telefônica a um Datanet-30, que é um processador de transmissões especializado, de programa gravado. Além do contrôle da linha 0 Datanet-30 executa ainda numerosas funções do sistema monitor, e especialmente o contrôle das atividades. O GE-235, o computador central com uma capacidade de 16.000 palavras e um ciclo de memória de 6 micro-segundos, é encarregado das principais tarefas de compilação, de execução e de edição, e o cadastro de discos GE-204 oferece uma capacidade de memória de 28 milhões de caracteres. O Mark I é, atualmente, o sistema em tempo parcial de uso mais corrente. Pusemos em uso 36 Mark 1 em 14 centros espalhados por todos os Estados Unidos, e 22 Mark I em 18 centros instalados na Europa ocidental e em outras partes do mundo. Considerado, geralmente, como o primeiro sistema em tempo parcial que obteve êxito comercial, o Mark I foi produzido em 1964, com a colaboração do Darmouth College. Nessas mesmas condições foi elaborada a linguagem Básica de John Kemeny. Essa linguagem é atualmente considerada como uma linguagem de programação fácil de ensinar, mas que permite, não obstante, processar problemas complexos.

A segunda rêde que examinaremos é um sistema de tempo parcial de grande envergadura, o Mark II (esquema 2). O sistema de transmissão pode $\mathrm{co}^{-}$ mandar até 200 terminais distanciados, de baixa velocidade. Dois de seus quatro processadores de transmissão $\mathrm{Da-}$ tanet-30 podem ser instalados longe do sistema central, a êles ligados por linhas telefônicas muito rápidas. Êles desempenham, então, as funções do concentrador, de que tratamos anteriormente. O processador central é um computador GE-635, com capacidade de 96.000 palavras e com ciclo de base de um micro-segundo, que utiliza como extensão de memória um tambor Univac de 783.000 palavras e com um tempo de acesso de 17 mili-segundos e com até 100 milhões de caracteres de memória a disco DSU 204. Atualmente, sete sistemas Mark II equipam quatro centros, que servem a uma clientela espalhada por todos os Estados Unidos. 
O sistema GE Resource (esquema 3) utiliza, como o Mark II o hardware 635, mas acha-se equipado com um sistema de transmissões com dois ramais, que controlam, de um lado, terminais lentos de teclado e, de outro, impressoras lineares e leitoras de cartões muito rápidas. Um sistema monitor especial, - Gecos III, comanda simultâneamente, unidades periféricas locais, bem como os terminais distanciados, lentos ou rápidos. Os usuários podem passar programas de diálogo, no sistema de tempo parcial, e por grupos de tarefas, no sistema de processamento diferido. Uma multiprogramação integral permite ao sistema alternar o processamento de um grande número de tarefas em tempo parcial e tarefas por grupos, a fim de reduzir o tempo de processamento dos trabalhos menores, e explorar ao máximo os recursos do sistema. Já temos um sistema Resource em utilização comercial e já estão previstos outros.

O esquema 4 representa nosso sistema mais recente, o Mark II-AX. Salvo no que se refere às transmissões, êsse sistema difere muito pouco do Mark II, quase que apenas no fato de que o sistema-cadastro, de 200 milhões de caracteres, compreende discos com cabeçote fixo muito mais rápidos. Em compensação, o sistema de transmissão foi inteiramente modificado. $O$ concentrador central é um computador de condução de processamento de tipo Gepac 4020, de 16.000 palavras e com um ciclo base de 1,6 micro-segundo. Está conectado ao 635 por um canal de conexão de memória e comanda todo o tráfego de transmissão do sistema. $\mathrm{O}$ concentrador central comanda oito concentradores periféricos, cada um por meio de uma linha telefônica de 2.400 bits por segundo.

Os concentradores periféricos, que são computadores de comunicação especialmente modificados, com memórias de 8.000 palavras com ciclos de base de 0,9 micro-segundos, podem comandar, cada um dêles, até 48 terminais com velocidades de linha que podem atingir a 30 caracteres por segundo. Os concentradores distantes são alimentados, comandados e testados pelo concentrador central, e podem funcionar de modo totalmente autônomo.

Instalamos o primeiro Mark II-AX em agôsto último, 13 em Cleveland, com os concentradores terminais instalados em seis cidades do país. Graças à utilização complementar de multiplexores, para a divisão das freqüências, êsse sistema serve, pràticamente, tôdas as aglomerações importantes dos Estados Unidos. Além disso, um sétimo concentrador afastado, que ligará, por satélite, os usuários britânicos à rêde, já se encontra em Londres e está sendo submetido aos últimos testes. Uma Iigação análoga, por satélite, em Paris, está em estudo. Prevemos a instalação de um certo número dêsses sistemas no decorrer dêste ano14 e do ano próximo.

APLICAÇŌES

Se bem que esta explanação tenha como tema central a tecnologia das rêdes de informática, gostariamos de assinalar os tipos de aplicaçőes atualmente em prática, nesses sistemas.

Em primeiro lugar, os estudos técnicos (engineering): soluçăo dos problemas de análise de rêdes elétricas,

13 e 14. 1969. (N. do T.) 
análise dos processos químicos, análise e concepção das estruturas, análises hidráulicas, concepção de máquinas e geometria coordenada. Conforme já observamos, são, êstes, alguns exemplos das possibilidades oferecidas ao usuário para elevar sua produtividade, graças à rapidez das respostas e à continuidade do diálogo obtido com uma rêde de informática.

Em segundo lugar, os estatísticos utilizam-se de assistência prestada por êsses serviços para a criação e a interpretação de dados experimentais, elaboração de técnicas de estatística standard, tais como a regressão, a análise dos fatôres e a análise das variantes na simulação Monte-Carlo do comportamento estatístico dos modelos operacionais, bem como para tarefas tão terra-à-terra como a coleta dos dados, o armazenamento, a edição, a tabulação e a mostragem gráfica.

Em terceiro lugar, a planificação e o contrôle dos recursos: utilização da programação linear e das técnicas de transferência e de distribuição associadas, e mais particularmente exploração de possibilidades tais como a edição on line $e$ a passagem de pequenos ensaios programados, em forma de diálogo rápido, seguido pelo desenrolar de programas mais importantes no mesmo sistema, mas com execução diferida por grupos.

Em quarto lugar, a previsão e a planificação de emprêsas: marketing, previsões econômicas, análise dos riscos, análise do caminho crítico, simulação de projetos e elaboração de modelos gerais. O sistema constitui um laboratório aberto ao diálogo, no qual novas Idéias podem ser elaboradas e testadas ràpidamente, com a participação e as contribuições simultâneas de numerosas pessoas.

Em quinto lugar, a planificação da fabricação, o contrôle de produção e de qualidade: programação do contrôle numérico, estimativa das cargas dos equipamentos, da produção e dos preços de custo, elaboração de gráficos de contrôle de qualidade, análise dos limites do contrôle e determinação das dimensões das amostras.

Em sexto lugar, a análise financeira: custos de produção, investimentos, cash flow, orçamento e análise das depreciações e das amortizações.

Evidentemente, os sistemas de rêdes internacionais que estamos implantando tornaräo possivel uma gama de aplicações inteiramente novas. Algumas dessas aplicações, como, por exemplo, o registro das encomendas, o contrôle dos estoques e a computação da produção em organizações com várias unidades de produção podem ser previstos para um futuro muito próximo.

\section{TENDÊNCIAS FUTURAS}

Isto nos conduz ao último tema desta explanação: as tendências futuras da tecnologia das rêdes. No que se refere aos terminais, há dois setores nos quais prevemos desenvolvimentos particularmente interessantes, para os próximos anos. Primeiro, o campo dos pequenos terminais econômicos. 0 exemplo mais significativo é o próprio combinado telefônico, com teclado em lugar do disco e uma resposta por síntese vocal, na saída. A despeito das limitações evidentes que apresentam êsses aparelhos dão resultados satis fatórios em matéria de entrada de dados e de consulta; além disso, custam 
quase duas vêzes menos que os teleimpressores mais baratos. Terminais muito econômicos oferecem um atrativo especial, na medida em que permitem ao consumidor utilizar os serviços do computador. Muitos são os que antevêem como possível um setor importante de serviços individuais, sem falar nas prestigiosas máquinas de somar, para auxiliar as donas de casa fazer suas contas $\theta$ as crianças a resolver seus problemas de aritmética. Imaginem, por exemplo, um serviço de cadastros tipo "SVP", que, conforme a estrutura de suas perguntas, os ajudasse a encontrar um apartamento, um bom negóclo, um emprêgo, um restaurante interessante ou um local agradável onde passar as próximas férias. Imagine um serviço de ensino a domicílio, com uma vasta gama de cursos especialmente programados com perguntas e respostas, destinados aos adultos, e uma série completa de exercícios para os estudantes, transformando os deveres em uma atividade muito mais rendosa, adaptada ao ritmo, às capacidades e às necessidades particulares de cada aluno. $O$ segundo campo de desenvolvimento dos terminais é o da arte gráfica. Prevemos a aparição de um certo número de dispositivos, entre os quais:

terminais de composição fotográfica, que utilizarão a rêde para obter e editar um texto; ademals, que produzirão uma matriz inteiramente marginada em quaisquer tipos de caracteres, com diferentes talhes, em negrita e em itálico...;

consolos de visualização gráfica, que terão uma lógica1s e uma memória suficientes para gerar segmentos, arcos e outros elementos gráficos, sob - contrôle de subprogramas registra- dos no sistema central, e possibilitando gerar figuras complexas;

- impressoras de transmissão direta de imagens, utilizando as técnicas xerográficas e eletrostáticas, que lerão, bit por bit, a imagem mostrada em uma tela catódica, a fim de imprimir, segundo seja pedido, um documento para uma decisão de grau elevado.

Nenhuma dessas possibilldades é nova, mas atualmente êsses terminais gráficos são muito dispendiosos e de oferta limitada. Dentro de alguns anos, serão moeda corrente, e pouco mais caros que os teleimpressores atuais.

No campo das transmissões, creio que a inovação mais espetacular será a integração de sistemas locais e regionais com rêdes de computadores múltiplos, graças aos quais o terminal do usuário, em qualquer ponto da rêde, poderá ter acesso a qualquer dos computadores dessa rêde, $\theta$, de um modo mais geral, um programa, passando por qualquer computador da rêde, poderá ter acesso a cadastros ou criar novos programas em qualquer outro computador. Graças à utilização combinada de ligaçōes vila satélite e de linhas terrestres, bem como à criação de centros de troca de dados, essas super-rêdes cobrirão primeiro os Estados Unidos, depois a Europa ocidental e por fim uma grande parte do mundo.

Essas rêdes proporcionarão progressos espetaculares nas atividades logísticas em grande escala - remessa, contrôle de balanços comerciais, intercâmbio de informaçöes técnicas etc. $\mathrm{Na}$ medida em que as estruturas dessas rêdes forem universais, será

15. Dispositivo eletrónico que determina quais as instruços que um computador pode executar. (N. do T.) 
possível, pela primeira vez, desenvolver aplicações de teleprocessamento de modo progressivo, fundado no princípio de tentativas, e experimentar, econômicamente, idéias novas.

As rêdes intercontinentais dêsse tipo podem parecer-nos remotas, hoje em dia. De fato, temos a impressão de que a maior parte das importantes aplicações do futuro são absolutamente imprevisiveis e que mesmo as aplicações logísticas, que parecem ser evidentes, levarão muitos anos para se desenvolver e para serem utilizadas. Mas não devemos esquecer que o impacto da divisão das cargas por várias zonas horárias deve compensar de modo significativo o aumento do custo das comunicações, ainda que a rêde seja utilizada para serviços locais. A interconexão se torna quase um subproduto. Isto nos torna muito otimistas quanto à realização dessas superrêdes.

No que diz respeito ao processamento central, prevemos três tendências principais. Primeiro, pode-se predizer, sem errar, que a capacidade do sistema central aumentará consideràvelmente. Uma das condições essenciais para a flexibilidade das rêdes universais é a de que nenhuma aplicação deve requerer mais que uma pequena fração da capacidade da rêde. Em conseqüência, o aumento da envergadura das rêdes requer um acréscimo substancial do rendimento da unidade central. As rêdes universais de grande envergadura, atualmente existentes, têm um limite máximo de cêrca de 100 utilizadores ativos. Essa cifra deveria, cremos, mais que duplicar, nos próximos anos.

Em segundo lugar, a disponibilidade e a confiabilidade da estação cen- tral serão objeto de uma atenção tôda especial. Hoje, poucos sistemas comerciais de uso universal atingem um nivel de disponibilidade global que ultrapasse $97 \%$ ou $98 \%$, e o tempo médio que decorre entre duas interrupções de uma certa duração não é, certamente, superior a 6 ou 8 horas. Numerosas aplicações importantes exigirão uma disponibilidade da ordem de $99,9 \%$ ou interrupçōes acumuladas inferiores a oito horas por dia, e um tempo médio entre as interrupções medido em dias. Essas exigências serão muito provàvelmente satisfeitas graças a sistemas centrais modulares, constituidos a partir de conjuntos de computadores múltiplos de acoplagem livre, capazes de configurações dinâmicas, bloqueando automàticamente os componentes provisòriamente não utilizáveis, o que acarretará um decréscimo da capacidade, mas garantirá um serviço permanente e uniforme.

Em terceiro lugar, cremos que os futuros sistemas monitores terão uma envergadura suficiente para suprimir totalmente a distinçăo entre o tempo parcial e o processamento por grupos à distância. Essas modalidades de operação serão apenas dois elementos de um continuum de recursos e de prioridades e o usuário poderá fazer o levantamento prévio da combinação de resposta-capacidade-memória-velocidade de terminal etc. que mais se adapte a suas necessidades e a seu orçamento.

No domínio do armazenamento, como no processamento central, a capacidade e a confiabilidade realizarăo progressos consideráveis. As necessidades de capacidade referentes às memórias a disco atingirão provàvelmen- 
te - para as grandes rêdes - $10^{\circ}$ octets, pelo menos, e mesmo 1010 octets. Para permitir os recarregamentos de cadastros e satisfazer os outros imperativos relacionados com volumes importantes para uma baixa freqüência dé acesso, êsses sistemas necessitarăo das memórias de arquivamento lentas, de capacidade dez vêzes superior à das memórias anteriores. Êsses sistemas terão uma confiabilidade elevada, graças à conservação seletiva dos cadastros e à atualizaçăo das informaçōes, bem como a um dispositivo de retomada e de reinicio automático, que recolocará os cadastros em seu estado anterior correto, em caso de êrro ou de contaminação acidental pelos próprios programas dos usuários.

Essas melhorias, associadas à criação de estações centrais de computadores múltiplos, sòmente poderão ser obtidas através de uma modificação fundamental da relação entre as unidades de processamento e o sistema de cadastros. O contrôle do acesso ao cadastro e a determinação das posiçőes dêste último não mais serão confiadas ao sistema central, mas a processadores de cadastros, sistemas autônomos inteiramente responsáveis pela operação dos cadastros, e que funcionarão, em verdade, como supervisores, exercendo uma autoridade absoluta sôbre o processamento dos pedidos de constituição, ou de destruição de cadastros, e 0 dos pedidos de leitura e de escrita nos cadastros existentes, pedidos emitidos pelos diferentes computadores de uma estação central complexa.

A maior parte dessas modificações sobrevirá muito ràpidamente. A tecnologia de base já foi, pràticamente, adquirida, e vários dêsses desenvolvimentos já atingiram o estágio dos testes operacionais. Dentro de cinco anos, veremos rêdes de informática intercontinentais, que terão atingido a maturidade, servindo a dezenas de miIhares de usuários, que se comunicarăo entre si. Essas rêdes caracterizarse-ão pela amplidăo de seus serviços, por uma confiabilidade optima $\theta$ por um custo altamente competitivo. Disto resultará, para as indústrias dạ informática e das transmissões, uma avalancha impressionante de aplicaçőes, de possibilidade e de produtos inteiramente novos, com inumeráveis mercados, bem como uma modificação irreversível das características do processamento e das transmissōes convencionais. E isto será apenas o comêço. 